\title{
Human gastric mucosal hydrophobicity does not decrease with Helicobacter pylori infection or chronological age
}

\author{
Mohammed S Al-Marhoon BSc MD PhD ${ }^{1}$, Sheila Nunn BSc PhD², Roger W Soames BSc PhD 3
}

MS Al-Marhoon, S Nunn, RW Soames. Human gastric mucosal hydrophobicity does not decrease with Helicobacter pylori infection or chronological age. Can J Gastroenterol 2005; 19(1):37-41.

BACKGROUND AND AIMS: Infection with cytotoxin-associated gene A (cagA) Helicobacter pylori is associated with severe gastric diseases. Previous studies in humans have reported a decreased gastric hydrophobicity with $\mathrm{H}$ pylori infection. The aim of the present study was to differentiate between the effect of cagA+ and cagA-strains on gastric mucus hydrophobicity.

METHODS: One hundred patients without peptic ulcers and not on medication were randomly recruited from endoscopy clinics; each patient had six biopsies. Contact angle measurements were performed using a goniometer assisted by computer software. $H$ pylori status was assessed by histology, Campylobacter-like organism test and culture, and cagA + status was determined by polymerase chain reaction.

RESULTS: In age- and sex-matched patients, there was no significant difference $(\mathrm{P}=0.27)$ in contact angle between $\mathrm{H}$ pylori-positive $\left(61 \pm 2.8^{\circ}\right)$ and $H$ pylori-negative patients $\left(65.5 \pm 3.0^{\circ}\right)$. There was also no significant difference $(\mathrm{P}=0.36)$ in contact angle among $H$ pylorinegative, cag $\mathrm{A}-$ and $\mathrm{cag} \mathrm{A}+$ patients $\left(65.5 \pm 3.0^{\circ}, 58.6 \pm 3.6^{\circ}\right.$ and $63.4 \pm 4.9^{\circ}$, respectively). However, a trend of increased mean contact angles in cag $\mathrm{A}+$ compared with cag $\mathrm{A}-$ and $\mathrm{H}$ pylori-negative patients was observed in patients 50 years and younger $\left(68.3 \pm 8.3^{\circ}, 61.1 \pm 6.1^{\circ}\right.$ and $63.6 \pm 2.2^{\circ}$, respectively; $\left.\mathrm{P}=0.70\right)$ and in patients without atrophy $\left(71.1 \pm 8^{\circ}, 59.6 \pm 4^{\circ}\right.$ and $66 \pm 2^{\circ}$, respectively; $\left.\mathrm{P}=0.30\right)$. In addition, there was no significant correlation between contact angles and patient age $(\mathrm{r}=0.104, \mathrm{P}=0.306)$.

CONCLUSIONS: The present study shows that $H$ pylori infection and the chronological age have no effect on the gastric mucus hydrophobicity, but it highlights a trend of increased mucus hydrophobicity with cagA + infection that needs to be supported by future studies.

Key Words: Age; CagA+; Gastric; Helicobacter pylori; Hydrophobicity
L'hydrophobie de la muqueuse gastrique humaine ne diminue pas par suite d'une infection à Helicobacter pylori ou avec l'âge chronologique

HISTORIQUE ET BUT : Une infection à Helicobacter pylori associée au gène $\mathrm{A}$ de la cytotoxine $(\mathrm{cag} \mathrm{A})$ est reliée à de graves maladies gastriques. Des études antérieures sur des humains ont fait état d'une diminution de l'hydrophobie par suite d'une infection à $H$ pylori. La présente étude visait à distinguer l'effet des souches cagA+ et cagA- sur l'hydrophobie de la muqueuse gastrique.

MÉTHODOLOGIE : Cent patients sans ulcère gastroduodénal ne prenant pas de médicaments ont été recrutés au hasard dans des cliniques d'endoscopie. Chaque patient a subi six biopsies. Des mesures d'angle de contact ont été exécutées au moyen d'un radiogoniomètre assisté par ordinateur. Le statut de $H$ pylori a été évalué au moyen d'une histologie, et de l'épreuve et de la culture d'un organisme semblable au Campilobacter, et le statut de l'infection à cag $\mathrm{A}+$ a été établi par réaction en chaîne de la polymérase.

RÉSULTATS : Chez des parents appariés selon l'âge et le sexe, on n'a remarqué aucune différence significative $(\mathrm{P}=0,27)$ dans l'angle de contact entre les patients positifs à $H$ pylori $\left(61 \pm 2,8^{\circ}\right)$ et ceux qui y étaient négatifs $\left(65,5 \pm 3,0^{\circ}\right)$. Il n'y avait pas de différence significative $(\mathrm{P}=0,36)$ dans l'angle de contact entre les patients négatifs à $\mathrm{H}$ pylori, infectés à cag $\mathrm{A}-$ et à cagA $+\left(65,5 \pm 3,0^{\circ}, 58,6 \pm 3,6^{\circ}\right.$ et $63,4 \pm 4,9^{\circ}$, respectivement $)$. Cependant, une tendance à l'accroissement des angles de contact moyens dans l'infection cag $\mathrm{A}+$ par rapport à l'infection cagA- et aux patients négatifs à $H$ pylori a été observée chez des patients de 50 ans est moins $\left(68,3 \pm 8,3^{\circ}, 61,1 \pm 6,1^{\circ}\right.$ et $63,6 \pm 2,2^{\circ}$, respectivement; $\left.\mathrm{P}=0,70\right)$ et chez des patients sans atrophie $\left(71,1 \pm 8^{\circ}, 59,6 \pm 4^{\circ}\right.$ et $66 \pm 2^{\circ}$, respectivement; $\mathrm{P}=0,30$ ). De plus, il n'existait aucune corrélation significative entre les angles de contact et l'âge des patients $(\mathrm{r}=0,104, \mathrm{P}=0,306)$.

CONCLUSIONS : La présente étude révèle que l'infection à $H$ pylori et que l'âge chronologique n'ont aucun effet sur l'hydrophobie de la muqueuse gastrique, mais elle souligne une tendance vers l'accroissement de l'hydrophobie de la muqueuse par suite d'une infection à cag $\mathrm{A}+$, laquelle doit être étayée par de futures études.
$\mathrm{T}_{\mathrm{s}}^{\mathrm{h}}$, he hydrophobic or water-repellent mucus lining of the stomach plays an important role in protecting the gastric mucosa from acid and peptic digestion (1). In 1983, it was reported (1) that canine gastric mucosa has clear hydrophobic properties as determined by contact angle analysis. Since this observation, reports from many investigators have indicated that the stomach of all mammalian species tested, including humans, have nonwettable properties that appear to be attributable to the hydrophobic characteristics of the overlying mucus gel layer (2). Goggin et al (3) and Spychal et al (4) used a technique that permitted contact angle analysis of endoscopic antral biopsy samples.

\footnotetext{
${ }^{1}$ School of Biomedical Sciences, University of Leeds, Leeds; ${ }^{2}$ School for Health, University of Durham, Durham, United Kingdom; ${ }^{3}$ School of Biomedical Sciences, James Cook University, Townsville, Australia

Correspondence: Dr Mohammed S Al-Marhoon, 27 Stonelea Court, Leeds LS7 2UH, United Kingdom. Telephone 44-0-778-859-1932, fax 44-0-113-343-4228, e-mail almarhoon@hotmail.com

Received for publication May 17, 2004. Accepted September 28, 2004
} 
The hydrophobicity of the gastric antral mucosa of peptic ulcer patients has been found to be significantly lower than that of healthy volunteers (5). The effect of Helicobacter pylori on human mucosal hydrophobicity has been investigated using the contact angle technique, with most studies $(3,5,6)$ reporting a decrease in mucosal hydrophobicity with $H$ pylori infection compared with noninfected controls. In contrast, Day et al (7) have shown that H pylori (mouse-adapted strain SS1) had no effect on the gastric mucus surface hydrophobicity in C57BL/6 and gld mice despite mucosal inflammation. The aim of the present study was to differentiate between the effect of $\mathrm{H}$ pylori cytotoxin-associated gene $\mathrm{A}(\mathrm{cag} \mathrm{A})+$ and cagAstrains on human gastric mucosal hydrophobicity.

\section{Subjects}

\section{METHODS}

One hundred patients were randomly recruited from endoscopy clinics in the North of England without prior knowledge of their $H$ pylori status. The study was approved by the Leeds Health Authority clinical research ethics committee and the York research ethics committee. Written consent was obtained from and information sheets given to each patient. Patients were included in the study if they were not taking acid suppressive drugs, nonsteroidal anti-inflammatory drugs or receiving treatment for $\mathrm{H}$ pylori, but excluded if they were known or found to have peptic ulcer disease or gastric cancer (to eliminate the possible effects of previous pathologies on the surface hydrophobicity). Following recruitment into the study, one patient was subsequently excluded due to the presence of duodenal ulcer. Of the remaining 99 patients, $42(42 \%)$ were male and $57(58 \%)$ female with mean ages of $46 \pm 11$ and $51 \pm 15$ years, respectively. Six biopsies were taken from each patient (five from the antrum and one from the body of the stomach). Of the six biopsies, one was used for the measurement of gastric mucosal hydrophobicity (taken from the greater curvature), one was for polymerase chain reaction (PCR), one was for culture of H pylori, one was for the Campylobacter-like organism test and two were examined for histology (antrum and body).

\section{H pylori status}

$\mathrm{H}$ pylori infection was assessed by histology, culture and PCR. Patients were considered to be $H$ pylori-positive if two or more of the above tests were positive.

\section{PCR}

Identification of the $H$ pylori cag $\mathrm{A}+$ strain was carried out by PCR using two pairs of primers: cagA (primer 1: $5^{\prime}$-CTC AAA TCC CCC TTA CCA AAC TC-3'; primer 2: 5'-GAG ATT AAG GAT TTC CAA AAA GAC TCT AA-3', product size 130 base pairs) and urease $C$ (primer 1: 5'-ATA AGG TGG CTC CGG TCG TT-3'; primer 2: 5'-TGG CTC AAT TGG TTA GGG TGT-3', product size 120 base pairs), synthesized by Dr F Lewis (University of Leeds). DNA extraction and PCR were performed using standard protocols.

\section{H pylori culture}

H pylori culture was performed as described by Goodwin (8).

\section{Contact angle (hydrophobicity) measurement}

The biopsy was collected in a $10 \mathrm{~mL}$ saline glass bottle and transported at room temperature. The biopsy was placed on a wax plate and put under a dissecting microscope (Vickers Instruments
173282, United Kingdom). It was then cleaned of debris, oriented with the mucus layer facing upwards and placed on a clean glass slide. The biopsy was allowed to air dry for $30 \mathrm{~min}$ until it assumed a matte appearance.

Contact angle measurements were performed as described by Spychal et al (4), with few modifications. The biopsy sample wettability (hydrophobicity) was measured using a calibrated contact angle goniometer (made by the Department of Physics and Astronomy, University of Leeds) assisted by computer software (Accuware version 2.1, Automated Visual Inspection, USA). The fresh biopsy on the glass slide was placed on the goniometer stage and a $0.5 \mu \mathrm{l}$ drop of $0.9 \%$ saline deposited from a $0.2 \mathrm{~mL}$ microsyringe (Gilmont instruments, GS-1100, USA). Droplets were illuminated by a sodium lamp and imaged with a zoom lens (Navitar Inc, USA) coupled via an extension tube to a charge-coupled device camera (Hamamatsu C3077, Hamamatsu Photonics Ltd, United Kingdom). The picture of the drop on the biopsy surface was then captured by the camera and transferred to the computer, where the sides of the drop were magnified and the angle readings taken at a high magnification.

For each biopsy, six contact angle readings were taken by applying three different saline drops (two readings/drop, one from each side). In addition, to assess repeatability, the contact angle readings for 22 patients were repeated (six additional readings for each biopsy, total 12 readings). The contact angle measurements representing the hydrophobicity of the gastric mucus layer were performed without prior knowledge of the patients' $\mathrm{H}$ pylori status or histological findings. The contact angle was determined by measuring the angle between the solid-liquid line and the liquid-air line.

\section{Statistical analysis of data}

Results were analysed using SPSS software version 10.1 (SPSS Inc, USA) and expressed as mean \pm SEM. Statistical significance was tested using ANOVA and Student's $t$ test (paired and unpaired). The level of statistical significance was taken at $\mathrm{P}<0.05$. Pearson correlation coefficient was used in the determination of the associations between parameters.

\section{RESULTS}

Of the 99 patients studied, 69 were $H$ pylori-negative and 30 were $H$ pylori-positive; of these 30,10 were cagA+, 18 were cagA- and two were undetermined. Nine patients had atrophic gastritis, of which six were infected with cagA+. The mean contact angle for the 99 patients was $64.5 \pm 0.8^{\circ}$, with values ranging from $21.0^{\circ}$ to $127.8^{\circ}$. When patients were classified according to $H$ pylori infection, there was no significant difference $(\mathrm{P}=0.16)$ in contact angle between $H$ pylori-positive $\left(61 \pm 2.9^{\circ}, \mathrm{n}=30\right)$ and $H$ pylori-negative patients $\left(66 \pm 2.0^{\circ}\right.$, $\mathrm{n}=69$ ). In age- and sex-matched patients, there was no significant difference $(\mathrm{P}=0.27)$ in contact angle between $\mathrm{H}$ pyloripositive $\left(61 \pm 2.8^{\circ}, \mathrm{n}=30\right)$ and $H$ pylori-negative patients $\left(65.5 \pm 3^{\circ}, \mathrm{n}=30\right)$ (Figure 1).

There was also no significant difference $(\mathrm{P}=0.36)$ in contact angle in age- and sex-matched patients among $\mathrm{H}$ pylorinegative $\left(65.5 \pm 3^{\circ}, \mathrm{n}=30\right)$, cagA- $\left(58.6 \pm 3.6^{\circ}, \mathrm{n}=18\right)$ and cagA + patients $\left(63.4 \pm 4.9^{\circ}, \mathrm{n}=10\right)$. However, in patients 50 years of age or younger, there was a nonsignificant $(\mathrm{P}=0.70)$ trend of increased mean contact angles in cagA + patients compared with cag $\mathrm{A}-$ and $\mathrm{H}$ pylori-negative patients $\left(68.3 \pm 8.3^{\circ}, \mathrm{n}=5 ; 61.1 \pm 6.1^{\circ}, \mathrm{n}=9 ;\right.$ and $63.6 \pm 2.2^{\circ}, \mathrm{n}=39$, respectively). Also, in patients without atrophy, a similar 


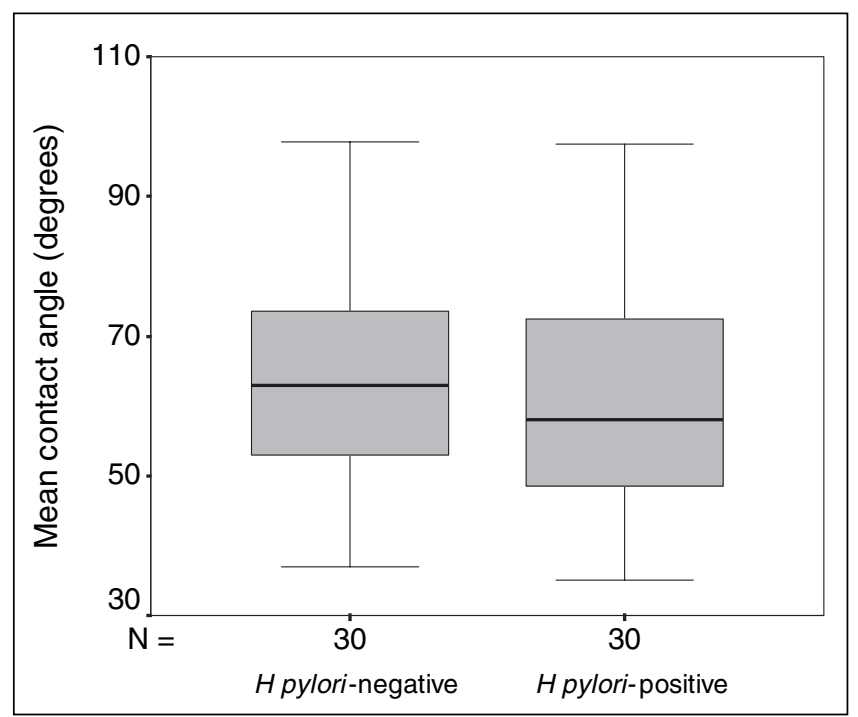

Figure 1) Box plot comparing the mean contact angle of age- and sexmatched Helicobacter pylori-positive patients with $\mathrm{H}$ pylori-negative patients. No significant difference was observed $(P=0.27)$

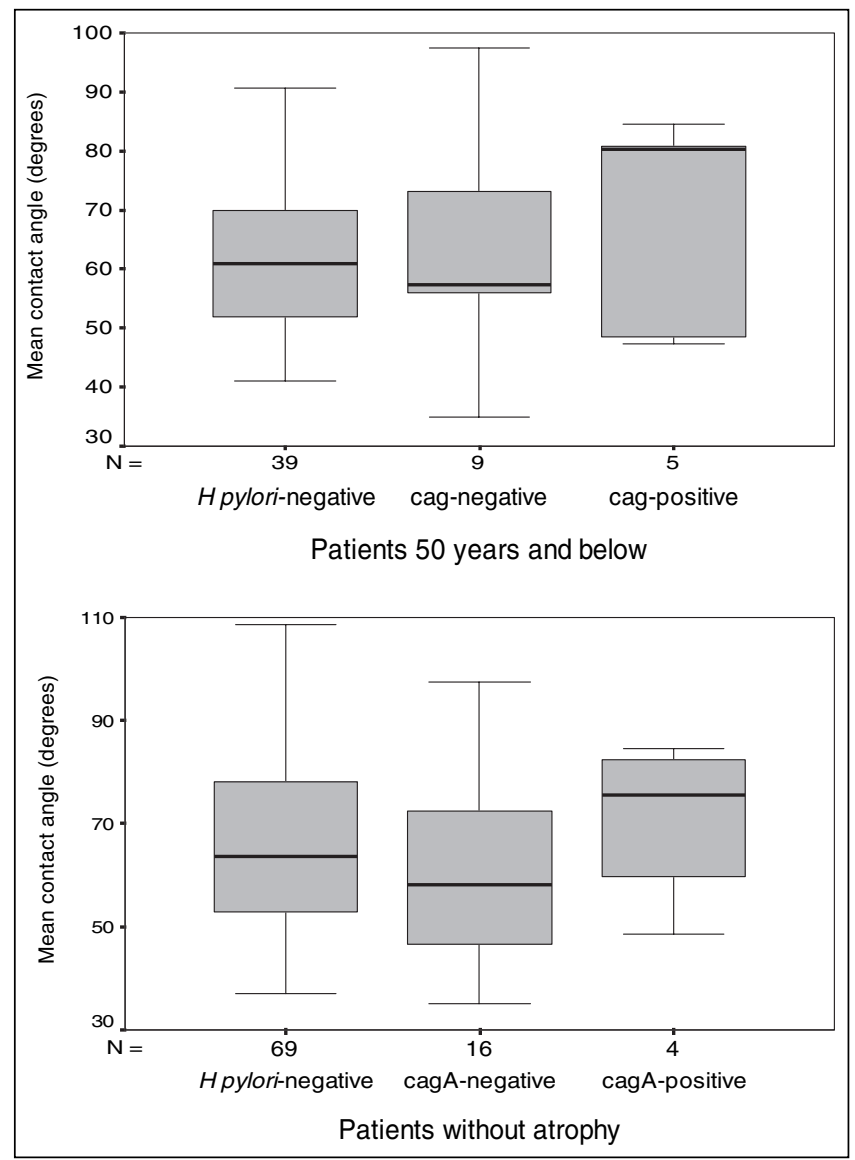

Figure 2) Categorization of the mean contact angle according to Helicobacter pylori infection in patients 50 years of age and younger (upper chart) and patients without atrophy (lower chart). Patients with cytotoxin-associated gene A (cagA) + had a trend toward higher mean contact angles (not statistically significant), than cagA- and $\mathrm{H}$ pylorinegative patients, both in patients 50 years of age and younger and in those without atrophy

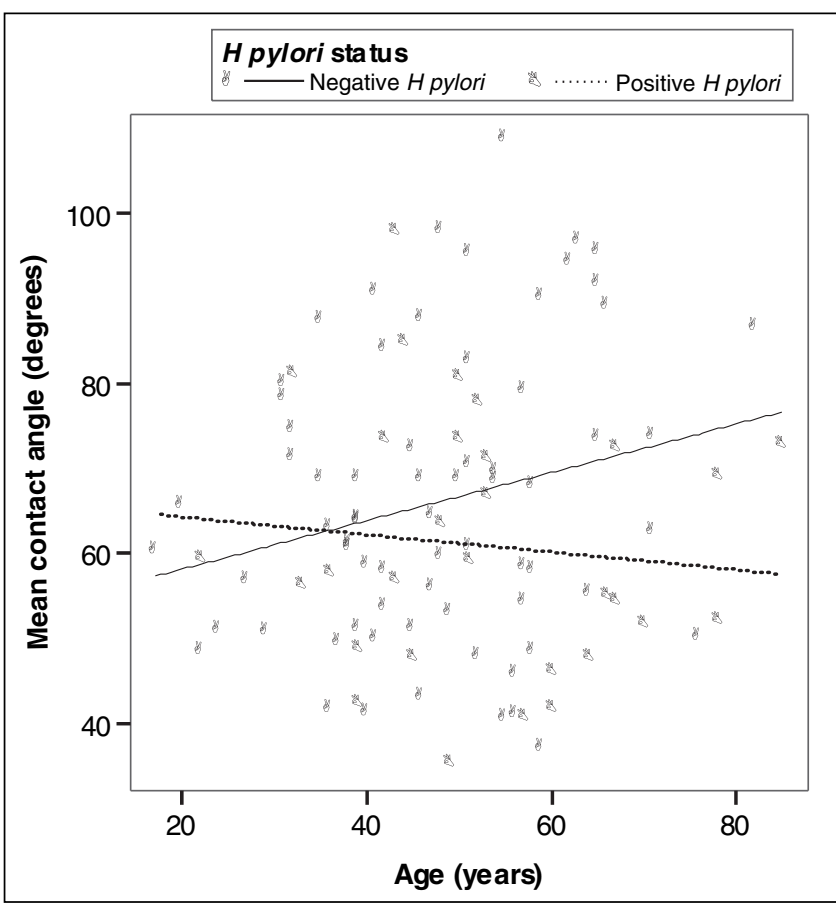

Figure 3) Nonsignificant correlation between gastric mucosal hydrophobicity and age $(r=0.104, P=0.306)$

nonsignificant $(\mathrm{P}=0.30)$ trend was observed in cagA+ patients compared with cagA- and $\mathrm{H}$ pylori-negative patients $\left(71.1 \pm 8^{\circ}, \mathrm{n}=4 ; 59.6 \pm 4^{\circ}, \mathrm{n}=16\right.$; and $66 \pm 2^{\circ}, \mathrm{n}=69$, respectively $)$ (Figure 2).

Considering the sex of the patient, there was no significant difference $(\mathrm{P}=0.277)$ in the mean contact angle between males $\left(62.4 \pm 2.2^{\circ}, \mathrm{n}=42\right)$ and females $\left(66.1 \pm 2.4^{\circ}, \mathrm{n}=57\right)$. To evaluate the effect of age on gastric mucosal hydrophobicity, patients were divided into three age groups that reflected the age distribution in the entire study group: group I, 40 years of age or younger; group II, 41 to 64 years of age and group III, 65 years of age and older (9). In the present study, there was no significant difference $(\mathrm{P}=0.231)$ in the mean contact angles among the different age groups $\left(60.6 \pm 2.3^{\circ}, n=29 ; 65.1 \pm 2.5^{\circ}, n=55\right.$; and $69.8 \pm 4.0^{\circ}, \mathrm{n}=15$, respectively). Within each age group there was no significant difference in mean contact angle among $\mathrm{H}$ pylori-negative, cag $\mathrm{A}-$ and cagA+ patients $(\mathrm{P}=0.836, \mathrm{P}=0.737$ and $\mathrm{P}=0.062$ for groups I, II and III, respectively). In addition, there was no significant correlation between hydrophobicity and patient age $(\mathrm{r}=0.104, \mathrm{P}=0.306)$. Also, there was no significant correlation between hydrophobicity and age in infected and uninfected patients $(\mathrm{r}=-0.101$, $\mathrm{P}=0.594$ and $\mathrm{r}=0.227, \mathrm{P}=0.061$, respectively) (Figure 3).

To determine the impact of the severity of gastritis on the surface hydrophobicity measurements, the mean contact angle was compared in groups of patients with normal histology and those with different grades of gastritis based on antral histology. There was no significant difference $(\mathrm{P}=0.599$, one-way ANOVA) between the groups. In addition, when both the factors of gastritis and the infecting $H$ pylori strain were considered, their interaction had no significant effect on the mean contact angle readings $(\mathrm{P}=0.368$, two-way ANOVA). 
The contact angle measurements for the first 22 patients were repeated twice (six readings on each occasion) to assess intraobserver repeatability. There was no evidence of bias between the two measurements $(\mathrm{P}=0.950$, paired Student's $t$ test $)$.

\section{DISCUSSION}

The stomachs of all mammalian species, including humans, have nonwettable properties (1) that appear to be attributed to the hydrophobic characteristics of the overlying mucus gel layer $(2,10)$. The hydrophobic mucus lining of the stomach plays an important role in gastric cytoprotection (1). Lichtenberger et al (11) have shown that rats injected with prostaglandin $E_{2}$ had higher gastric mucosal concentrations of phospholipids and surfactants than controls, indicating the importance of prostaglandin $\mathrm{E}_{2}$ in enhancing gastric hydrophobicity. The measurement of contact angles in the determination of surface hydrophobicity, which is a biophysical property of tissue surfaces, yields values that closely agrees with those obtained by methods that do not rely on contact angles (12).

Previous studies $(5,6,13)$ in humans have reported decreased gastric hydrophobicity with $\mathrm{H}$ pylori infection. In the present study, there was no significant difference in the mean contact angle (hydrophobicity) between age- and sexmatched $H$ pylori-positive and $H$ pylori-negative patients. The contact angle readings in the present study for the control subjects $\left(66 \pm 2.0^{\circ}, \mathrm{n}=69\right)$ were comparable with those obtained by Spychal et al (5) $\left(69.8 \pm 0.9^{\circ}, \mathrm{n}=75\right)$ and Goggin et al (6) $\left(69.8 \pm 0.9^{\circ}, n=40\right)$. However, the possible reasons that may explain why these studies found reduced gastric hydrophobicity in $\mathrm{H}$ pylori infection and the present study did not are as follows. First, they included patients with duodenal and gastric ulcer disease in their study groups which could have had deleterious effects on the surface hydrophobicity on their own, whereas the present study excluded all these patients, including those who had a past history of duodenal or gastric ulcer disease. Asante et al (14) observed that $H$ pylori-infected patients with duodenal ulcer had lower gastric hydrophobicity than infected patients with gastritis alone, but it was not clear whether it was $H$ pylori infection or the ulceration that initiated the reduction in hydrophobicity. Second, they did not age and sex match the patients and controls in their studies. Finally, they used a less precise method for contact angle measurements compared with the present study, which used computer software. In addition, these earlier studies did not differentiate between cag $\mathrm{A}+$ and cag $\mathrm{A}-$ patients.

In the present study, there was no significant difference in the mean contact angle among age- and sex-matched cagA+, cagA- and $\mathrm{H}$ pylori-negative patients. However, in patients without atrophy and those 50 years of age or younger, cagA+ patients tended to have a higher mean contact angle than cagA- and $\mathrm{H}$ pylori-negative patients; however, the difference was not statistically significant and could be attributed to biological variation, with the contact angle values ranging from $21.0^{\circ}$ to $127.8^{\circ}$.

The present study used a similar technique for contact angle measurements as that described by Spychal et al (4), with few modifications. The advantages of the Spychal et al (4) technique in using human biopsy specimens for hydrophobicity studies were its practicality and the fact that it enabled many subjects to be studied and followed up. However, there are problems associated with using biopsy specimens (15). First, the biopsy size limits the volume of water droplets that can be formed on the mucus surface, thereby reducing the accuracy of the surface property determinations. Second, the biopsy surfaces are rough and heterogeneous, leading to the production of sessile drops. Finally, the trauma involved in obtaining endoscopic biopsies could disrupt the mucus surface and, hence, may not give a true indication of the in situ surface properties.

The axisymmetric drop shape analysis-diameter (ADSA-D) technique developed by Skinner et al (16) for the determination of hydrophobicity in rabbit gastric mucosa was aimed at overcoming the problem of sessile drop formation on rough surfaces. Although the ADSA-D technique avoids the inaccuracies inherent in measuring the contact angle on rough surfaces such as gastric biopsies, it is not practical in humans, because it requires large tissue sections rather than biopsies.

Animal studies on the effect of $H$ pylori on gastric hydrophobicity have given contradictory results. Day et al (7) have shown that $H$ pylori had no effect on mucus surface hydrophobicity despite mucosal inflammation. In a model of a mouse-adapted H pylori strain (SS1) used to infect C57BL/6 and gld mice, the contact angle readings were obtained by the ADSA-D technique. However, Lichtenberger et al (17) reported reductions in the hydrophobicity of gastric mucosa following Helicobacter felis infection of C57BL/6 mice, and proposed that the reduction in surface hydrophobicity is an early event predisposing to the development of subsequent gastritis.

In the present study, there was no significant difference in the mean contact angle in patients from different age groups. In addition, there was no significant correlation between hydrophobicity and age. However, when $H$ pylori infection was considered, a nonsignificant trend of increasing hydrophobicity in uninfected patients and decreasing hydrophobicity in infected patients was observed, especially in those 65 years of age and older. It is possible that $H$ pylori infection and old age have a synergistic effect on reducing the mucosal surface hydrophobicity. Nevertheless, Hackelsberger et al (9) have shown that age decreases gastric mucosal hydrophobicity independently from $H$ pylori infection, which is not supported by results from the present study. A possible explanation for this discordance in the results is the geographical variation in the diet, because, as shown by Lichtenberger et al (11), the surface active phospholipids are important determinants for gastric mucosal hydrophobicity.

The present study highlights the fact that the hypothesis that $H$ pylori causes peptic ulcers by reducing the mucosal layer hydrophobicity may not be valid (5). The decreased gastric hydrophobicity with $H$ pylori infection reported in previous studies could possibly be the consequence of associated gastric diseases rather than the cause of it. In contrast, we speculate that it may be possible that increased gastric hydrophobicity associated with cagA + infection is an early change in the process of infection that favours a better $H$ pylori colonization and the decreased hydrophobicity reported by other studies is a late consequence of the ulceration induced by $\mathrm{H}$ pylori infection. This may possibly explain the high association of cagA + infections with severe gastroduodenal diseases. However, given the small number of cagA + patients in the present study, the above suggestions remain very speculative and requires further investigation with a larger sample size. 
ACKNOWLEDGEMENTS: This work was funded by Sultan Qaboos University (Sultanate of Oman) and supported by the University of Leeds. Our thanks to Dr Mark Denyer (Senior Clinical Lecturer in Medicine, Seacroft University Hospital), Dr Sean Kelly (Consultant in Gastroenterology, York District Hospital) and Andrea Reilly (Nurse Endoscopist, St James's University Hospital) for providing the gastric biopsies. From the University of Leeds, our thanks to Professor Stephen Evans, Dr Fraser Lewis and Mr Andy West for allowing the use of their laboratory facilities for contact angle measurement, polymerase chain reaction and Helicobacter pylori culture, respectively. Finally, the authors would like to thank all the patients who have voluntarily participated in this research.

\section{REFERENCES}

1. Hills BA, Butler BD, Lichtenberger LM. Gastric mucosal barrier: Hydrophobic lining to the lumen of the stomach. Am J Physiol 1983;244:G561-8.

2. Lichtenberger LM. The effect of Helicobacter pylori on the surface hydrophobicity and phospholipid composition of the gastric mucosa. In: Hunt RH, Tytgat GNJ, eds. Helicobacter pylori: Basic Mechanisms to Clinical Cure 1996. London: Kluwer Academic Publishers, 1996:92-7.

3. Goggin PM, Northfield TC, Spychal RT. Factors affecting gastric mucosal hydrophobicity in man. Scand J Gastroenterol Suppl 1991;181:65-73.

4. Spychal RT, Marrero JM, Saverymuttu SH, Northfield TC. Measurement of the surface hydrophobicity of human gastrointestinal mucosa. Gastroenterology 1989;97:104-11.

5. Spychal RT, Goggin PM, Marrero JM, et al. Surface hydrophobicity of gastric mucosa in peptic ulcer disease. Relationship to gastritis and Campylobacter pylori infection. Gastroenterology 1990;98:1250-4.

6. Goggin PM, Marrero JM, Spychal RT, Jackson PA, Corbishley CM, Northfield TC. Surface hydrophobicity of gastric mucosa in
Helicobacter pylori infection: Effect of clearance and eradication. Gastroenterology 1992;103:1486-90.

7. Day AS, Jones NL, Policova Z, et al. Characterization of virulence factors of mouse-adapted Helicobacter pylori strain SS1 and effects on gastric hydrophobicity. Dig Dis Sci 2001;46:1943-51.

8. Goodwin S. Detection of H pylori by biopsy urease, histology and culture. In: Clayton CL, Mobley HL, eds. Helicobacter pylori Protocols. New Jersey: Human Press, 1997:7-18.

9. Hackelsberger A, Platzer U, Nilius M, et al. Age and Helicobacter pylori decrease gastric mucosal surface hydrophobicity independently. Gut 1998;43:465-9.

10. Lichtenberger LM. The hydrophobic barrier properties of gastrointestinal mucus. Annu Rev Physiol 1995;57:565-83.

11. Lichtenberger LM, Graziani LA, Dial EJ, Butler BD, Hills BA. Role of surface-active phospholipids in gastric cytoprotection. Science 1983;219:1327-9.

12. Neumann AW, Absolom DR, Francis DW, et al. Measurement of surface tensions of blood cells and proteins. Ann N Y Acad Sci 1983;416:276-98.

13. Go MF, Lew GM, Lichtenberger LM, Genta RM, Graham DY. Gastric mucosal hydrophobicity and Helicobacter pylori: Response to antimicrobial therapy. Am J Gastroenterol 1993;88:1362-5.

14. Asante M, Ahmed H, Patel P, et al. Gastric mucosal hydrophobicity in duodenal ulceration: Role of Helicobacter pylori infection density and mucus lipids. Gastroenterology 1997;113:449-54

15. Mack DR, Sherman PM. Hydrophobicity and gastrointestinal tract: Methods of determination, its source and implications for bacterial adherence. Colloids Surf B Biointerfaces 1999; 15:355-63.

16. Skinner FK, Rotenberg Y, Neumann AW. Contact angle measurement from the contact diameter of sessile drops by means of a modified axisymmetric drop shape analysis. J Colloid Interface Sci 1989;130:25-34.

17. Lichtenberger LM, Dial EJ, Ottlecz A, Romero JJ, Lechago J, Fox JG. Attenuation of hydrophobic phospholipid barrier is an early event in Helicobacter felis-induced gastritis in mice. Dig Dis Sci 1999;44:108-15. 


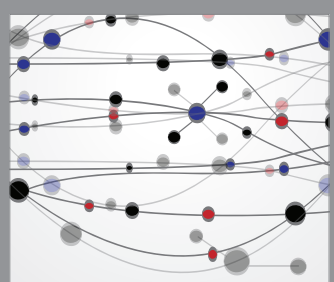

The Scientific World Journal
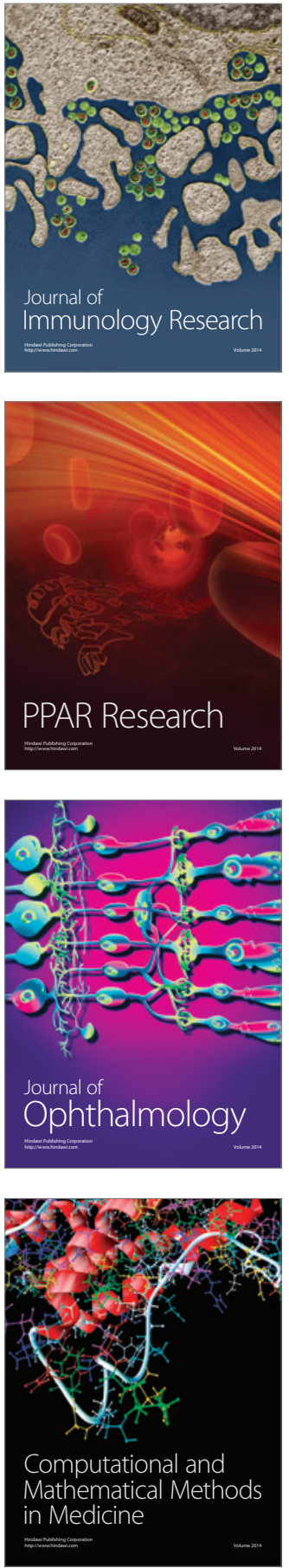

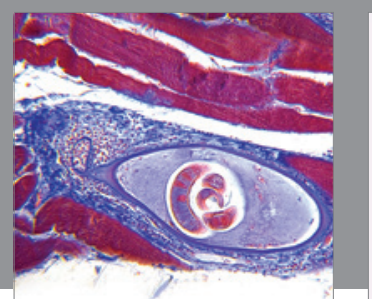

Gastroenterology Research and Practice

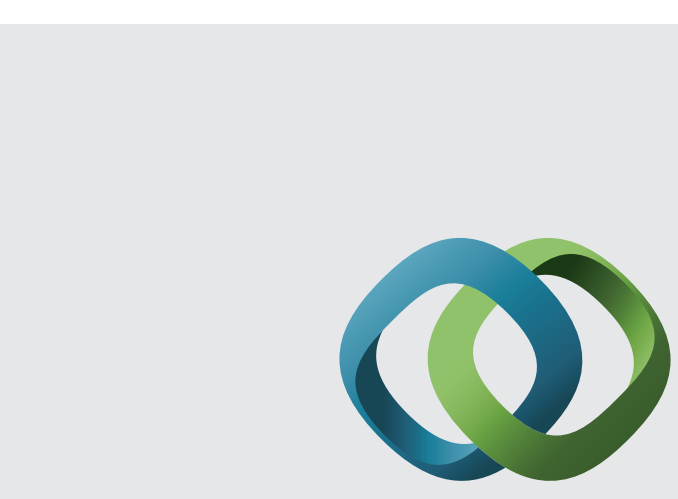

\section{Hindawi}

Submit your manuscripts at

http://www.hindawi.com
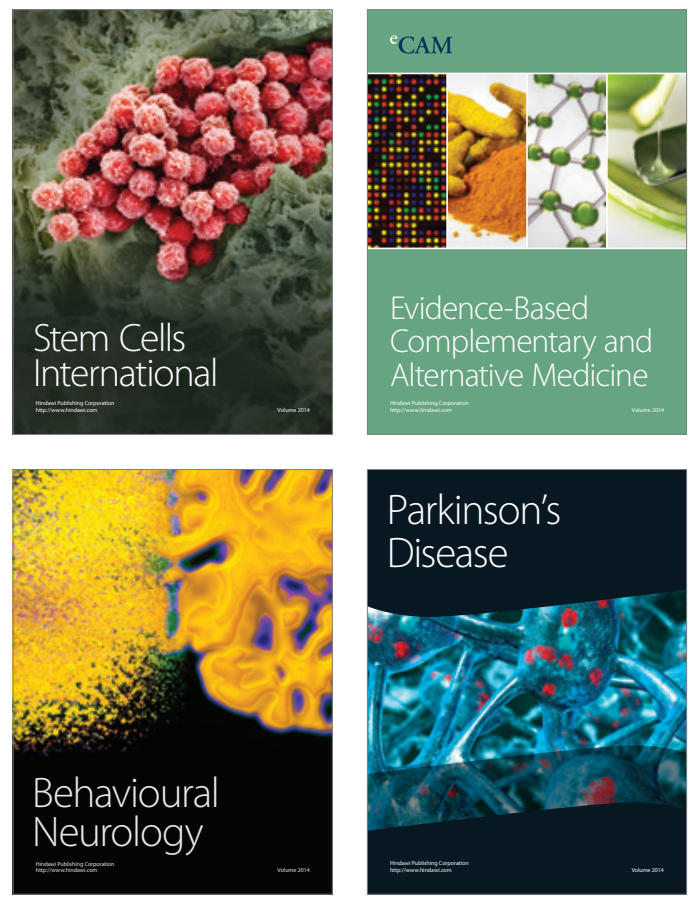
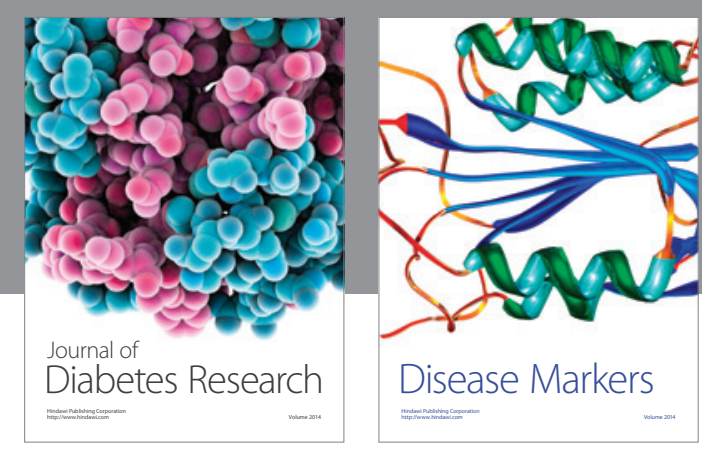

Disease Markers
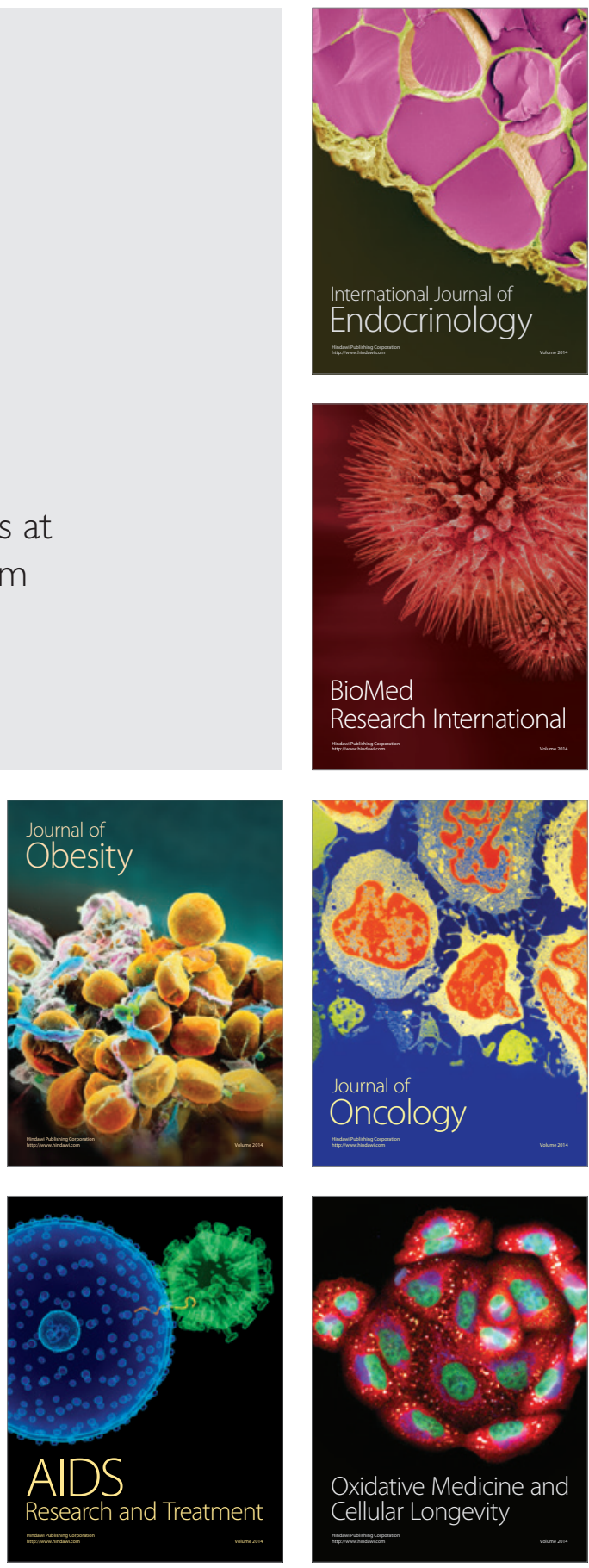